\title{
Statistical Analysis of House Construction Capacity Dynamics in ex-USSR Countries
}

\author{
A.P. Tsypin ${ }^{1, *}$, N.P. Persteneva ${ }^{1}$, S.A. Bannikov ${ }^{2}$ and T.V. Lebedeva ${ }^{3}$ \\ *Corresponding author: zipin@yandex.ru \\ ${ }^{1}$ Samara State University of Economics, Samara, Russia \\ ${ }^{2}$ Financial University under the Government of the Russian Federation, Russia, Moscow \\ ${ }^{3}$ Orenburg State University, Russia, Orenburg
}

\begin{abstract}
The relevance of the article is explained by the necessity of building more precise forecasts of developing socio-economic phenomena characterizing complex dynamics. The goal lies in analyzing the dynamics of launching of residential units in the post-Soviet countries and building a forecast with the account of the retrospective path movement of the indicator. The appliance of the "changing the growth (fall)" econometric model in the studied time-series has allowed to predict in a more precise way their path movement. The significance of the obtained results both for econometrics and residential property market economy are apparent and lie in mastering the methodology of building complex socio-economic phenomena, among which is the launching of residential units in the post-Soviet countries.
\end{abstract}

Keywords: dynamics, housing, historical time-series, periodization, forecasting, econometric modeling.

\section{Introduction}

The study of socio-economic phenomena and processes in the long-term retrospective is one of the goals of econometrics and it allows to identify isomorphic development periods, establish the influence of the factors on the pattern of behavior of the time series, to create more exact forecasts. In this regard the analysis of the launching of residential units in the post-Soviet countries for the years from 1946 to 2017 is a relevant objective.

The quantitive research of the dynamics of house construction in the USSR and the post-Soviet countries (from the historical point of view) was conducted by economists, statisticians, sociologists, historians and so on. Such a diversity of scientific directions stipulated the difference in methods and goals of their research works.

The historical time-series of house construction during the times of the USSR are mentioned in scientific literature, mainly from the point of view of separate regions and cities. Generally research works were dedicated to the history of industrial reclamation of the territories and to the connected with them rates of house construction. A considerable number of works have been analyzed on such regions as Siberia and Ural $[1,2]$ and industrial regions of the European part of the country [3]. Some of the works were dedicated to specific problems, for example, to the problem of house construction in the Soviet village of Central Russia and the pre-war period [4], to the post-war reconstruction of the cities [5].

Survey scientific works on the tendencies and forecast of the residential property market in CIS countries were made by Kuznetsova [6] and Salagor [7]. The time-series of house construction of separate countries were analyzed in the works on: Kazakhstan [8], Belarus [9], the countries of Central Asia and Caucasus [10], the Ukraine [11], the Baltic States [12].

In the Russian Federation the research works of house construction dynamics in general have a regional character (in the context of subjects of the Federation and federal districts), but some of the works were made on the country level. The work of Skorik, Lozovskaya, Kowalewski, [13], in which the methods of adaptive forecasting and seasonal indexes are used, presents the greatest interest from the point of view of statistics.

\section{Problem Statement}

Transformation of the economy sets a task of reconsidering the mechanisms of phenomena' and processes' development mechanisms. The residential property market is not an exception. In fact it was formed on the post-Soviet territory only in 1990-ties. The dynamics of its indicators is characterized by significant structural changes, which doesn't permit to use simple models for describing the tendencies. We suppose that this problem deserves a deeper consideration and using for complex econometrical models.

\section{Research Questions}

The econometrical tools should encourage obtaining of the models of residential units' launching that adequately reflect the factual levels which will allow to build more precise forecasts of phenomena development in the future. But the available today approach based on the analytical leveling-off doesn't permit to do this. That is why we should turn 
to another class of econometrical models, namely to regressive models with dummies which will lead to increased accuracy of the forecasts being made.

\section{Purpose of the Study}

Resting on the theoretical and practical works in the examined area one can formulate he goal of the conducted research which lies in analyzing the dynamics of launching of house construction in the post-Soviet countries and building a forecast taking into consideration the retrospective indicator's path movement.

The object of this research is the time series of launching of residential units in Russia, its subject is complex dynamics of the index and ability to build a forecast of its further development.

\section{Research Methods}

During the years of its development econometrics has developed a wide range of methods for analyzing and forecasting the time series having a complex structure. In such cases the model is presented as a number of elements for describing statistical characteristics of real statistically distributed socio-economic processes. Thus, A.A. Bolshakov and R.N. Karimov define 4 components of the time series [14]:

$$
Y(t)=B(t)+C(t)+X(t)+N(t)
$$

where: $\mathrm{B}(\mathrm{t})$ is a trend; $\mathrm{C}(\mathrm{t})$ is a periodic function with fixed periods; $\mathrm{X}(\mathrm{t})$ is a distributed process with a zero-mean; $\mathrm{N}(\mathrm{t})$ is a statistically distributed error.

According to V.A. Bessonov, the structure of the time series should consist of the following elements [15]:

$$
Y(t)=C(t)+S(t)+I(t)+T C(t)+U(t)
$$

Where: $\mathrm{C}(\mathrm{t})$ is a calendar component; $\mathrm{S}(\mathrm{t})$ is seasonal component; $\mathrm{I}(\mathrm{t})$ is an irregular component; TC(t) is a trendcycle component which can be developed into a secular trend и cycles; $\mathrm{U}(\mathrm{t})$ are unusual events.

All the mentioned above components are seldom used in real statistically distributed processes. The importance of each component depends on the problem being solved. That is why in terms of the extrapolation of the time series having a complex structure one should be careful and take into account the possibility of revealing frequent trends in their behaviour. In case there is no information about the functional dependence between the variable and the time factor you should the methods of moving average that makes the regular variable more defined. Along with this it is supposed that the variable should polynomially depend on the time factor. Adequacy and the accuracy of approximation on the basis of the method depends to a large extent on the chosen length of the average intervals and the chosen degree of the polynominal which limits the possibility of defining the structure of the analyzed time-series. In case it is necessary to build a forecast in practice is widely used the method of identifying the model of the time-series on the basis of the autoregression class and the on integrating moving average (ARIMA). But it also has a number of limiting factors both the possibility of its using for separate time-series and identifying in this context regularities. The use of these adaptive methods is connected with a number of difficulties as it is necessary to search for effective adjust constant terms.

To use the dynamics of the real process one can use the models of different classes taking into account that the statistical theory applied to it can be quite simple and the parameters of the models accepted an accurate interpretation. The econometric model of "changing the growth (fall)" satisfies these requirements and takes into account the sharp change of the level movement in the time-series. The regression model in this case looks in the following way:

$$
\tilde{y}_{t}=a_{0}+a_{1} t_{t}+\left(a_{1}^{\prime}-a_{1}\right) D_{t}+\varepsilon_{t}
$$

where: is a categorical variable reflecting a change in the trend slope in point $t^{\prime}$, which is defined in the following in the following way:

$$
D_{2 t}=\left\{\begin{array}{c}
t-t^{\prime}, \text { если } t>t^{\prime} \\
0, \text { если } t \leq t^{\prime}
\end{array}\right.
$$

The use of this model concerning the dynamics of house construction in the post-Soviet countries allows to define the real data more accurately and to build an adequate medium-term forecast.

\section{Findings}

While studying the house construction in the post-Soviet countries it is necessary to divide the existing historical time-series into 2 periods - these are the Soviet period (until the year of 1991) and the post-Soviet period. Its reasonability is explained by different approaches to construction starting from the sources of finding to the technologies of erecting buildings.

\subsection{The Soviet Period of House Construction Development}

The Soviet period of house construction development isn't uniform. The growth rates of launching of residential unit depended on a number of factors: from the econometric position of the USSR, from the impact of external threats, 
form the policy of the Communist party, the authority of the country's leader and so on. In this regard the dynamics of the analyzed indicator is presented with reference to five-year plans (Figure 1).

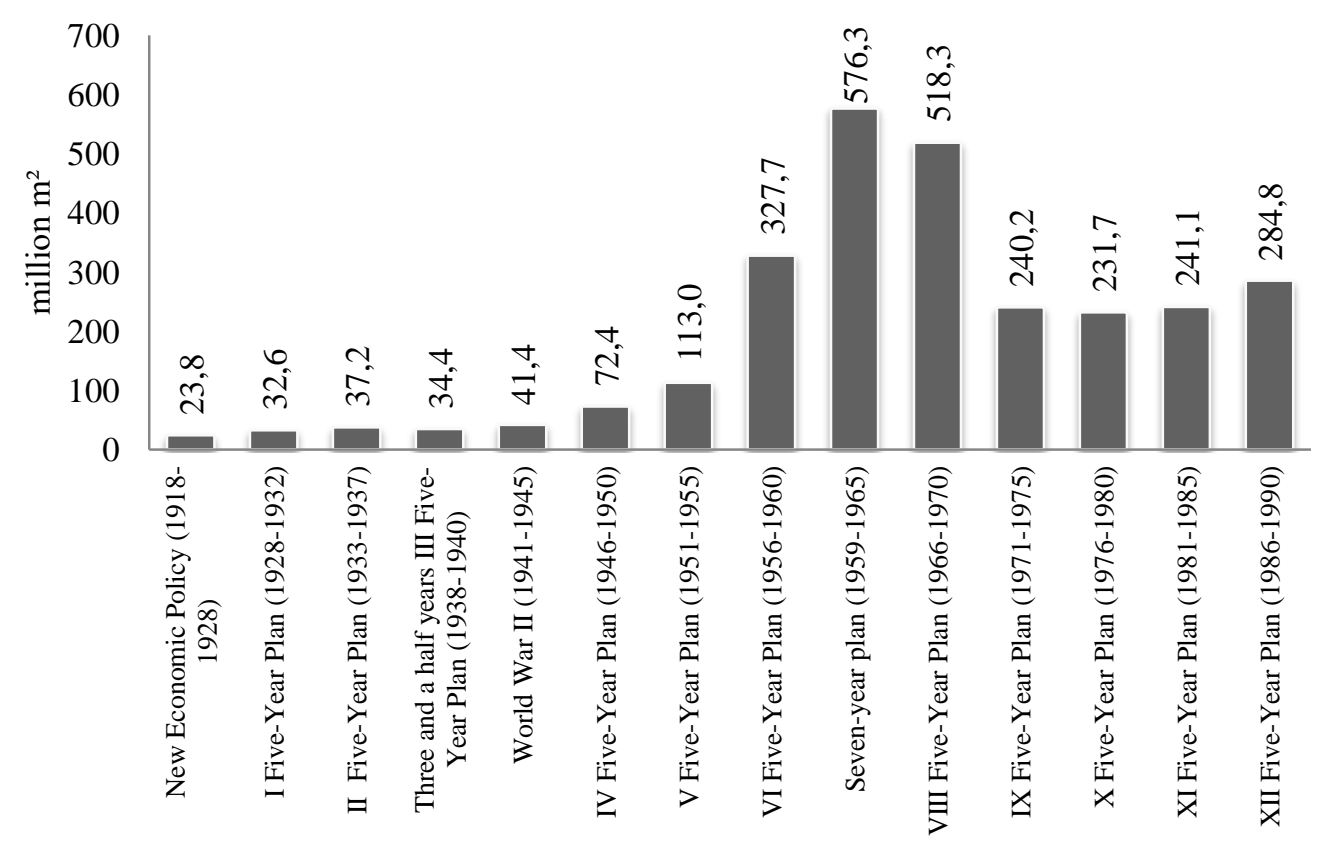

Figure 1. The dynamics of launching of house construction in the Soviet Unit, millions of square kilometers of total area (Source: compiled by the authors based on Yearbooks "National Economy of the USSR" [16]

According to the presented in figure 1 information, one can say that the largest volumes of launching of house construction fell on the post-war years. This was the period of N.S. Khrutshchev's governing (about 700 million of square meters were erected) and M.S. Gorbachev's governing (about 960 million of square meters were erected).

If we turn to the indicator's structure we shall find out that the largest volumes of housing construction were in the Russian Soviet Federative Socialist Republic, its part from 1960 to 1990 was higher than 50 percent of the All-Union meaning. The Ukraine took the second place with 15 percent. At the moment of the USSR's disintegration (1990) Uzbekistan (8.6 percent) and Kazakhstan (6.7 percent) reached significant results.

The evaluation of the growth rate in the Union countries (from 1990 to 1960) reveals that the largest growth is observed in Uzbekistan (4.8 times) and Tadzhikistan (4.0 times), while the average indicator in the Union was 1.4 times. It's obvious that such significant results in the countries of Middle Asia can be explained by low initial positions, still the considerable construction capacities allowed to relocate much of the population to comfortable housing accommodation. Thus, in 1960 the municipal residential properties in the USSR were 958 million of square kilometers of the total residential square, while by the year of 1989 this indicator had already reached 2890 million of square kilometers, which means that the growth was thrice. Now let's turn to the Post-Soviet period and evaluate the path movement of the analyzed indicator under the influence of transformation changes.

\subsection{Residential Construction in the Post-Soviet Countries in the Period from 1990 to 2017}

Before analyzing the situation with the launching of housing construction dynamics that occurred after the disintegration of the USSR it's necessary to point out that there is no information on a number of Post-Soviet countries. In accordance with the national statistical services one can build 12 time-series covering the period from 1990 to 2017. The information on Latvia, Lithuania and Turkmenia is not fully presented.

The graphical presentation of the time-series of the above mentioned countries has revealed the presence of structure changes that have led to the change of the path movement changes. To illustrate this, let's turn to picture 2 which shows the dynamics of housing construction in Russia. 


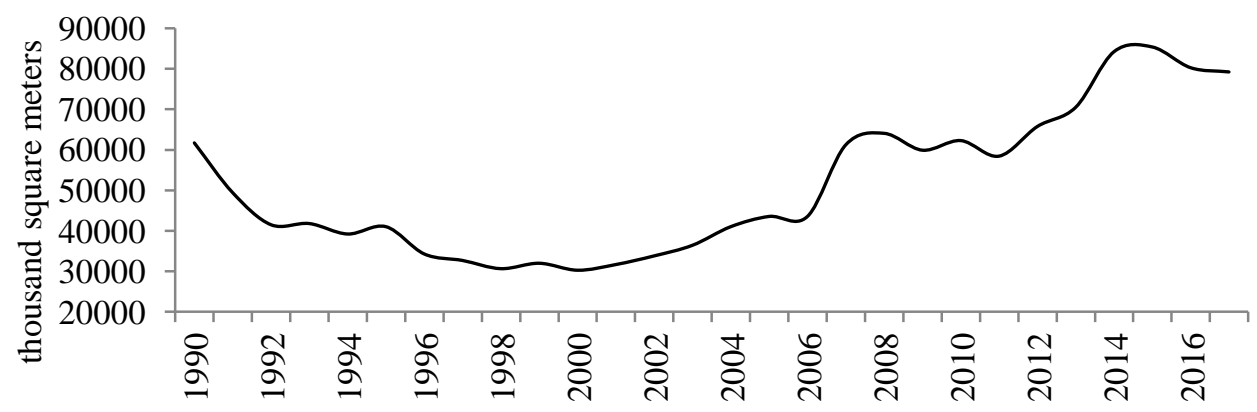

Figure 2. The dynamics of housing construction in Russia, thousands of square kilometers (Source: compiled by the authors based on Russian statistical yearbook [17])

We shall point out that only 6 countries (Russia, Belarus, Uzbekistan, Estonia and Georgia) from the analyzed 12 countries could exceed the level of the year of 1990 at the end of 2010's.

A complex path movement confines the range of the models suitable for describing (and forecasting) the built path. Thus, you can use the adaptive method of forecasting, as well as the methods of autoregression and moving average methods. In the first case we shall have to turn to a stationary series and lose part of the initial information, in the second case you should search for the optimal adjust constants which is not easy.

In our opinion, you should turn to the econometrical model of "changing the growth (fall)" which considers a sharp change of the level movement in the time-series. The evaluation of the parameters of this model in the packet STATISTICA leads to the results presented in table 1.

Table 1. The results of building a model of "changing the growth" of launching the housing construction in the Post-Soviet countries

\begin{tabular}{|l|r|r|r|r|r|r|c|}
\hline \multicolumn{1}{|c|}{ Indicators } & Intercept & $\mathrm{t}$ & $\mathrm{D} 1$ & $\mathrm{D} 2$ & $\mathrm{R}^{2}$ & $\begin{array}{c}\mathrm{F}- \\
\text { criterion }\end{array}$ & $\begin{array}{c}\text { Trend change } \\
\text { points, year }\end{array}$ \\
\hline RUS & 53,71 & $-2,26$ & 5,65 & - & 0,93 & 176,22 & 2000 \\
\hline UKR & 16,13 & $-0,98$ & 1,33 & - & 0,79 & 46,27 & 2000 \\
\hline BLR & 6,46 & $-0,70$ & 0,92 & $-0,38$ & 0,79 & 30,05 & 1995,2010 \\
\hline UZB & 10,53 & $-0,88$ & 1,15 & - & 0,71 & 31,09 & 1995 \\
\hline KAZ & 6,77 & $-0,61$ & 1,15 & - & 0,88 & 95,56 & 1999 \\
\hline GEO & 0,94 & $-0,09$ & 0,24 & - & 0,84 & 65,51 & 2001 \\
\hline AZE & 2,53 & $-0,21$ & 0,32 & - & 0,72 & 32,89 & 1999 \\
\hline MDA & 1,32 & $-0,10$ & 0,13 & - & 0,74 & 35,47 & 2000 \\
\hline KGZ & 1,73 & $-0,26$ & 0,30 & - & 0,90 & 111,20 & 1995 \\
\hline TJK & 2,05 & $-0,41$ & 0,46 & - & 0,94 & 211,30 & 1994 \\
\hline ARM & 1,61 & $-0,22$ & 0,25 & $-0,10$ & 0,68 & 16,74 & 1996,2010 \\
\hline
\end{tabular}

Source: compiled by the authors based on information from Russian statistical yearbook [17].

The data presented in table 1 indicate a good quality of the model.

The interpretation of the model coefficients lies in the following - until the year of 1998 (the point of changing the path movement of the time-series) reveals the fall of capacities of launching of the housing construction, in average on 2.22 million of square kilometers, after this period the movement changed for the growth, which on the average was 5.39 million of square kilometers.

As the regression model quite well describes the path movement of the time-series, we shall build a forecast for the period of years from 2018 to 2020 (table 2). 
Table 2. The point forecast of the housing construction launching in the post-Soviet countries for the period from 2018 to 2020

\begin{tabular}{|l|c|c|c|c|}
\hline \multirow{2}{*}{ Country } & \multirow{2}{*}{1990} & \multicolumn{3}{|c|}{ Forecast } \\
\cline { 3 - 5 } & & 2018 & 2019 & 2020 \\
\hline RUS & 61,7 & 89,8 & 93,2 & 96,6 \\
\hline ARM & 1,5 & 0,07 & 0,01 & 0,00 \\
\hline AZE & 2,9 & 2,68 & 2,79 & 2,91 \\
\hline BLR & 5,3 & 4,14 & 3,97 & 3,80 \\
\hline KAZ & 7,9 & 11,0 & 11,6 & 12,1 \\
\hline KGZ & 1,6 & 1,25 & 1,30 & 1,35 \\
\hline MDA & 1,6 & 0,73 & 0,75 & 0,78 \\
\hline TJK & 1,7 & 1,29 & 1,34 & 1,40 \\
\hline UZB & 9,9 & 11,3 & 11,6 & 11,8 \\
\hline UKR & 17,5 & 11,7 & 12,1 & 12,4 \\
\hline EST & 0,47 & 0,48 & 0,50 & 0,52 \\
\hline GEO & 1,01 & 2,36 & 2,51 & 2,66 \\
\hline
\end{tabular}

Source: compiled by the authors based on Yearbook "National Economy of the USSR" [16].

According to the presented forecast meanings once can make a conclusion about the studied indicator in the shortterm perspective, but in 2 countries from the analyzed 12 countries one can observe the reduction if the capacities of launching of housing construction. One should also point out the excess of the meanings of the year of 1990 in 2020 in such countries as Russia, Azerbaidzhan, Kazakhstan, Uzbekistan, Georgia and Estonia.

\section{Conclusion}

Concluding the analyzed study of the peculiarities of modeling and forecasting the capacities of launching of housing construction on the basis of long time-series one can make a number of deductions: firstly, the considerable structural changes are the important significant characteristic of historical (retrospective) time-series of Russian macroeconomic indicators of the post-Soviet countries; secondly, the econometrical models considering the structural changes of the time-series are best of all suitable for modeling and forecasting of the series with the changing path.

\section{References}

1. A.A. Dolgolyuk, The Siberian builders in 1946-1970. Novosibirsk: Parallel (2013). [in Rus.]

2. L.V. Nikitin, Square meters of success: Comparative dynamics of housing construction in the large cities of the Urals (the 1960ies - the 2000ies). Problems of the Russian History, 1(10), 409-431 (2010). [in Rus.].

3. T.A. Kiryushina, Housing policy in the USSR in the 30ies of the XX century (based on materials of the Penza region). News of the Penza State Pedagogical University of V.G. Belinsky, 23, 456-458 (2011). [in Rus.].

4. E.V. Bunina, To the question of the housing-construction in the Soviet village. MGSU Bulletin, 4(3). 54-58 (2010). [in Rus.].

5. E.E. Litvinenko, Restoration of housing stock of Stalingrad in 1945-1950. In S.G. Sidorov (Ed.), Military history of Russia: Problems, searches, decisions (pp. 235-241). Volgograd: VolSU (2016). [in Rus.].

6. M.Y. Kuznetsova, The review of the main tendencies of development of housing market in State Parties CIS. In V.A. Klimenov (Ed.), Youth, science, technologies: new ideas and prospect (MNT-2016) (pp. 59-62). Tomsk: TGASU (2016). [in Rus.].

7. R.A. Salagor, The analysis of development of the markets of residential real estate in the CIS countries. In P.P. Akhunov (Ed.), Beginning in Science (pp. 132-135). Ufa: Aeterna (2017). [in Rus.].

8. A.D. Esengaliyeva, Dynamics of development of branch of construction in the Republic of Kazakhstan. In T.L. Myagkova (Ed.), Social and economic technologies of development of society (pp. 60-63). Saratov, IIRPK (2018). [in Rus.].

9. V.N. Burakov, Construction of housing in BSSR in the 1920ies. Bulletin of the Brest University. Series 2. History. Economy. Law, 2, 12-17 (2013). [in Rus.].

10. R.B. Karamurzov, Living conditions of the population in the countries of Central Asia and South Caucasus (19902010). News of the Kabardino-Balkarian State University, 3-1, 104-111 (2013). [in Rus.].

11. L. Klyuchko, A.Lurye, Residential construction characteristics in the Ukraine (economical-geographical aspect). Regional Formation of the XXI century: Problems and Prospects, 6(15), 75-84 (2012). [in Rus.].

12. F. Wenner, Sustainable urban development and land value taxation: The case of Estonia. Land Use Policy, 77, 790800 (2018).

13. M.A. Skorik, A.N. Lozovskaya, Y.A. Kowalewski, Housing construction in the Russian Federation: dynamics and direction of development. Production Management: Theory, Methodology, Practice, 4, 56-61 (2016). [in Rus.].

14. A.A. Bolshakov, R.N. Karimov, Methods of processing of multidimensional data and time-series. Moscow: Hot line-Telecom (2016). [in Rus.]. 
15. V.A. Bessonov, Introduction to the analysis of the Russian macroeconomic dynamics of a transition period. Moscow: Institute of economy of transitional period (2003). [in Rus.].

16. Yearbook "National Economy of the USSR". Central Statistical Directorate. Retrieved from: http://istmat.info/node/433 (1991). [in Rus.].

17. Russian statistical yearbook. Federal State Statistics Service. Retrieved from: http://www.gks.ru/bgd/regl/b17_13/Main.htm (2017). [in Rus.]. 